\title{
EDITORIAL
}

\section{In This Issue: Community Care, Healing, and Excellence in Research}

\author{
Louise Acheson, MD, MS, Associate Editor \\ Departments of Family Medicine, Oncology, and Reproductive Biology, Case Western Reserve University, \\ University Hospitals Case Medical Center, Cleveland, Ohio
}

Ann Fam Med 2008:290-291. DOI: 10.1370/afm.871.

\section{COMMUNITY CARE}

1 This issue of the Annals features a special report ${ }^{1}$ describing how Community Care of North Carolina (CCNC) has improved quality and reduced total costs for care of Medicaid patients during the last decade. CCNC is a system of community health networks led by local primary care physicians that originated in rural areas. By linking clinicians in small primary care practices with local social services and Medicaid-supported resources, CCNC has been able to help manage patients with complex conditions and to collect and exchange data for quality improvement. Every patient is a member of a primary care practice. While "recognizing and celebrating regional differences," CCNC has grown to encompass 1,200 primary care practices and $80 \%$ of the state's Medicaid enrollees. In so doing, they have been able to measurably improve the care of some chronic diseases while saving an estimated $\$ 161$ million in Medicaid costs in 2006. ${ }^{1}$ A commentary by Tom Bodenheimer ${ }^{2}$ draws for us 7 lessons from North Carolina's experience. It appears that this model of collaboration between state insurance and primary care, centered in busy outpatient practices, "has moved beyond theory and could be implemented across the country."1

In CCNC, better primary care case management for chronic diseases saved on hospital services. In her essay, ${ }^{3}$ family physician Cherie Glazner wonders whether, with the advent of hospitalists, she still needs to be directly involved in her patients' hospital care. After a compelling personal experience she reflects, "It is not the 'basket of services'4 that creates a place for me in the ever-evolving ecosystem of high-tech hospitals, ... my role is to be my patients' advocate, a keeper of their stories, an audible voice in the cacophony of medicine... I cannot have a voice if I am not present." ${ }^{13}$

\section{HEALING}

This issue publishes a cluster of 3 articles on healing, by $\mathrm{Hsu}_{,}{ }^{5} \mathrm{Scott}^{6}{ }^{6}$ and Meza. ${ }^{7}$ It is challenging to research this ineffable process called healing. To do so, both Hsu and Scott use qualitative methods. Hsu and colleagues asked focus groups of nurses, physicians, medical assistants, and randomly selected patients to define healing and describe what facilitates or impedes it. ${ }^{5}$ The groups arrived at surprisingly convergent definitions: "Healing is a dynamic process of recovering from a trauma or illness by working toward realistic goals, restoring function, and regaining a personal sense of balance and peace. ${ }^{15}$ They heard from diverse participants that "healing is a journey," and "relationships are essential to healing." ${ }^{15}$ Scott and coinvestigators ${ }^{6}$ explored the healing relationship in in-depth interviews with exemplar primary care physician-healers and selected patients who had experienced healing relationships. These patients and physicians defined healing as transcendence of suffering, and they characterized healing relationships by "a nonjudgmental emotional bond," the clinician's conscious use of power for the patient's benefit, "a commitment to caring for patients over time," "hope," and "a sense of being known." ${ }^{16}$ Meza and Fahoome, ${ }^{7}$ finding similar constructs in the literature of healing, propose one of the first quantitative tools to measure healing. Their starting point is the patient's experience, because "[p]ersons, not diseases, can be healed." Their rigorous psychometric analysis "gives researchers a new tool to explore relationships between... health and health care."7

\section{EXCELLENCE IN QUALITATIVE RESEARCH METHODS}

How should one tell whether qualitative research methods are sound? Cohen and Crabtree present a systematic review of criteria for evaluating health-care-related 
qualitative research. ${ }^{8}$ They find general agreement on several features of good qualitative research, but go on to show that researchers' differing world views can pose a challenge. Contrasting paradigms lead to different, legitimate methods for addressing potential bias and ensuring that qualitative research is reliable and valid. Different criteria for methodologic rigor apply to different approaches to qualitative research.

\section{CLINICAL RESEARCH}

This issue includes two reports of original research on clinical topics.

Chew-Graham and colleagues report a qualitative interview study to understand how patients and their primary care clinicians recognize chronic fatigue syndrome, negotiate the diagnosis, and learn from a variety of sources how to manage it. ${ }^{9}$

Bogner and de Vries compare usual care with case management focused on medication adherence for older people with a combination of depression and hypertension. ${ }^{10}$ Their short-term outcomes of integrated case management are better than usual care, with increased adherence to both antihypertensive and depression medications, lower blood pressure, and resolution of depressive symptoms.

\section{EPIDEMIOLOGY RELEVANT TO PRIMARY CARE}

A continuous disease registry in the Netherlands allows family physicians to aggregate practice data to deterimine changes in the prevalence of various skin diseases over time. ${ }^{11}$

The work of Doubeni and colleagues ${ }^{12}$ suggests that 6 th graders' answers to 2 questions- "Do you have friends who smoke?" and "Would it be easy for you to get a cigarette?" — predict becoming a regular smoker by 10 th grade. Are you surprised that $21 \%$ of 6 th graders said it would be easy to get a cigarette and that one-third of 10th graders knew of a store that would sell cigarettes to youth?

Gramling and colleagues ${ }^{13}$ found that men who rated their 5-year risk of having a stroke or heart attack as "low" went on to have lower-than-expected mortality from cardiovascular disease (CVD) in the subsequent 15 years (controlling for Framingham risk score and other CVD risk factors). Does the men's perception of low risk stem from insider knowledge of their own health, or does optimism protect against cardiovascular events? It is interesting that Dutch investigators in general practice found similar optimistic perceptions of CVD risk among 4 out of 5 male patients with high CVD risk scores. ${ }^{14}$ Neither study observed such an optimistic bias among women.

Please share your thoughts about this issue by joining the Annals online discussion at http://www. AnnFamMed.org.

\section{References}

1. Steiner BD, Denham AC, Ashkin E, Newton WP, Wroth T, Dobson LA Jr. Community Care of North Carolina: improving care through community health networks. Ann Fam Med. 2008;6(4)361-367.

2. Bodenheimer T. North Carolina Medicaid: a fruitful payer-practice collaboration. Ann Fam Med. 2008;6(4)292-294.

3. Glazner C. Dinosaurs, hospital ecosystems, and the future of family medicine. Ann Fam Med. 2008;6(4)368-369.

4. Martin JC, Avant RF, Bowman MA, et al. The future of family medicine: a collaborative project of the family medicine community. Ann Fam Med. 2004;2(Suppl 1):S3-S32.

5. Hsu C, Phillips WR, Sherman KJ, Hawkes R, Cherkin DC. Healing in primary care: a vision shared by patients, physicians, nurses, and clinical staff. Ann Fam Med. 2008;6(4)307-314.

6. Scott JG, Cohen D, DiCicco-Bloom B, Miller WL, Stange KC, Crabtree BF. Understanding healing relationships in primary care. Ann Fam Med. 2008;6(4)315-322.

7. Meza JP, Fahoome GF. The development of an instrument for measuring healing. Ann Fam Med. 2008;6(4)355-360.

8. Cohen DJ, Crabtree BF. Evaluative criteria for qualitative research in health care: controversies and recommendations. Ann Fam Med. 2008;6(4)331-339.

9. Chew-Graham CA, Cahill G, Dowrick C, Wearden A, Peters S. Using multiple sources of knowledge to reach clinical understanding of chronic fatigue syndrome. Ann Fam Med. 2008;6(4)340-348.

10. Bogner HR, de Vries HF. Integration of depression and hypertension treatment: a pilot, randomized controlled trial. Ann Fam Med. 2008;6(4)295-301.

11. Verhoeven EWM, Kraaimaat FW, van Weel C, et al. Skin diseases in family medicine: prevalence and health care use. Ann Fam Med. 2008;6(4)349-354.

12. Doubeni CA, Li W, Fouayzi H, DiFranza JR. Perceived accessibility as a predictor of youth smoking. Ann Fam Med. 2008;6(4)323-330.

13. Gramling R, Klein W, Roberts M, Waring ME, Gramling D, Eaton CB. Self-rated cardiovascular risk and 15-year cardiovascular mortality. Ann Fam Med. 2008;6(4)302-306.

14. van der Weijden T, van Steenkiste B, Stoffers HEJH, Timmermans DRM, Grol R. Primary prevention of cardiovascular diseases in general practice: mismatch between cardiovascular risk and patients' risk perceptions. Med Decis Making. 2007;27(6):754-761. 